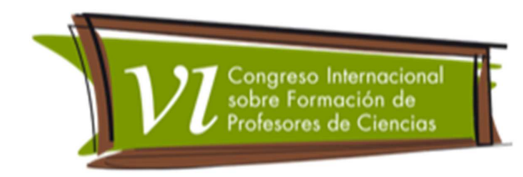

\title{
La influencia histórica del conocimiento tradicional en la construcción del conocimiento científico y procesos de apropiación durante la expedición botánica (desde un dialogo de saberes)
}

Millán Molina Claudia Patricia' ' García Edwin Germán ${ }^{2}$

Categoría 1. Reflexiones y experiencias desde la innovación en el aula

\section{Resumen}

En el marco de estudios sobre la línea de investigación historia y filosofía de las ciencias se presenta la siguiente experiencia educativa desarrollada como práctica docente con estudiantes de licenciatura en educación básica énfasis en ciencias naturales y educación ambiental, conforme a las particularidades del curso etno-educación y conocimiento del Instituto de Educación y Pedagogía de la Universidad del Valle.

Se propone desde la perspectiva sociocultural de la ciencia el dialogo de saberes como estrategia, para propiciar un encuentro entre el conocimiento tradicional y el conocimiento científico, realizando un reconocimiento a la diversidad cultural a través de un estudio de caso histórico sobre la expedición botánica y su implicaciones para la enseñanza de las ciencias naturales.

\section{Palabras Clave}

Dialogo de saberes, diversidad cultural

\section{Introducción}

La presente experiencia educativa genera espacios de reflexión crítica sobre los procesos de construcción del conocimiento en los cuales juega un papel importante los procesos de divulgación y apropiación científica. Por ello, se busca identificar hechos históricos que demuestran el intercambio de conocimientos, para establecer una relación dialógica entre el conocimiento tradicional y el conocimiento científico.

\footnotetext{
1 Universidad del Valle. claudiamillan37@yahoo.com.co

2 Universidad del Valle. edwingermangarcia@hotmail.com
} 
Revista Tecné, Episteme y Didaxis: TED. Año 2014, Número Extraordinario. ISSN Impreso: 0121-3814, ISSN web: 2323-0126

Memorias, Sexto Congreso Internacional sobre Formación de Profesores de Ciencias. 08 al 10 de octubre de 2014, Bogotá

Elkana (1983) sostiene que las ciencias no son remitidas exclusivamente desde las comunidades científicas centro - periferia, sino también del conocimiento tradicional, indicando que las ciencias son un sistema multicultural.

Por lo tanto, se pretende integrar el conocimiento tradicional en las ciencias, retomado historias de la botánica tradicional y la expedición botánica de Mutis. Para generar estrategias de enseñanza- aprendizaje en que: "Al mismo tiempo, la sociedad moderna y la rural podrían estar entrelazadas con la realidad de la sociedad del conocimiento" (Tinnaluck, 2004, pág. 29).

\section{Desarrollo}

La metodología de la presente experiencia educativa se basa en caracterizar desde el punto de vista histórico la cultura tradicional y la cultura científica como sistemas que interactúan y permiten la construcción del conocimiento generado en la expedición botánica.

Se toman como referentes tres sesiones organizadas de la siguiente manera:

\section{Sesión 1}

El propósito es interpretar la diversidad cultural a partir de descripciones superficiales o densas propuestas por Geertz (2003) a partir de la cual se realizaron dos actividades.

Actividad 1: La caja de pandora

Esta actividad se efectúa para ampliar la diferencia entre las descripciones superficiales y las descripciones densas. Por tanto, se solicita a tres estudiantes que observen por medio de dos orificios al interior de la caja de pandora, posteriormente, se solicita que describan lo que vieron sin evocar el nombre, para que los estudiantes presentes en el público lograran identificarlo

Las descripciones fueron las siguientes:

Estudiante 1: Es un ser vivo de color verde que se encuentra principalmente en lagos

Estudiante 2: Es un animal que puedes encontrarlo cuando caminas en una noche oscura por el bosque 
Revista Tecné, Episteme y Didaxis: TED. Año 2014, Número Extraordinario. ISSN Impreso: 0121-3814, ISSN web: 2323-0126 Memorias, Sexto Congreso Internacional sobre Formación de Profesores de Ciencias. 08 al 10 de octubre de 2014, Bogotá

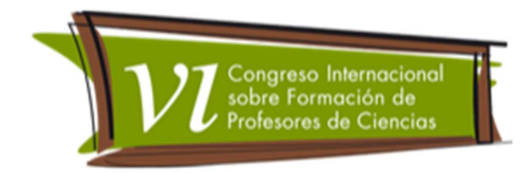

Estudiante 3: Cuando lo ves te asustas y produce asco

Los estudiantes presentes en el público al escuchar las descripciones pensaron que él estudiante 1, describía un sapo o un grillo; estudiante 2, describía un lobo o un búho; estudiante 3, describía cucarachas, serpientes, ratas o lombrices.

Posteriormente, se abre la caja de pandora para observar que en el interior se hallaba una rata. Con lo anterior, se pudo demostrar las múltiples interpretaciones que se pueden realizar de un mismo evento.

Seguidamente se preguntó: ¿qué significa una rata para nuestra cultura? Algunos respondieron; desaseo, enfermedades o un insulto porque se asocia con robo. Para contrastar este significado se procedió a desarrollar la actividad 2.

Actividad 2: video foro

Se proyecta el video:

Pacheco, J. (Productor). (2012). Templo de las ratas (serie de televisión). Perú. Panorama.

Se observa una legendaria expresión de Fe en el templo de las ratas de la India, y se inicia un foro donde se contrasta el significado de la rata como un animal sagrado para la cultura india, diverso al que se tiene en nuestra cultura. Se concluye que es importante dejar de lado las descripciones superficiales para interpretar las culturas mediante el uso de descripciones densas que permiten comprender el conocimiento que se gesta y valida en cada cultura. Las ciencias no se puede limitar a teorías, formulas o leyes; por tanto, se debe explorar en la historia para efectuar descripciones densas que permiten comprender como surgió o porque se generó determinado conocimiento.

Posteriormente, se realiza un corto debate donde los estudiantes consensan que la ciencia es un sistema cultural sometido al juicio y a la interpretación de otros sistemas culturales, y que cada sistema cultural es válido al interior de su propio contexto (Elkana, 1983, pág. 1-32)

Sesión 2

El propósito es discutir algunos decretos que el gobierno Colombiano ha generado desde 1991 para reconocer la diversidad cultural del país, debido a las múltiples manifestaciones efectuadas por las comunidades culturalmente 
Revista Tecné, Episteme y Didaxis: TED. Año 2014, Número Extraordinario. ISSN Impreso: 0121-3814, ISSN web: 2323-0126

Memorias, Sexto Congreso Internacional sobre Formación de Profesores de Ciencias. 08 al 10 de octubre de 2014, Bogotá

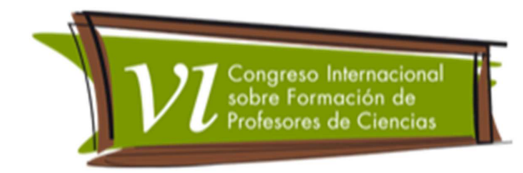

diferenciadas que históricamente han solicitado una educación acorde a sus necesidades y realidades culturales.

Para cumplir con este propósito se desarrollan dos actividades

Actividad 1: Video foro

Se proyectan los siguientes videos:

Guerra, A. (Productor). (2010). Súper O histórico (serie de televisión) Bogotá, Colombia. Señal Colombia

Mosquera, J. (comunicación personal, mayo 17, 2011)

Mazabuel, C. (comunicación personal, mayo 23, 2013)

Se concluye que en la constitución política colombiana se ha efectuado un reconocimiento a los grupos culturalmente diferenciados implementando la educación como un derecho, sin embargo, son pocas las escuelas que se preocupan por responder a las necesidades locales. Por tanto, la mayoría de las instituciones educativas se preocupan por responder a los requerimientos del ministerio de educación como por ejemplo las pruebas saber.

Actividad 2: juego de roles

Se solicita a los estudiantes formar grupos para asumir un rol como directivos institucionales, comunidades étnicas o docentes frente a la situación de incluir en la clase de Ciencias Naturales elementos reconocidos en el conocimiento tradicional.

Posteriormente, se discute la pertinencia de incluir en la clase de ciencias naturales teorías de sistemas culturales como el científico, el religioso y el tradicional que expliquen un mismo hecho y evoquen diversidad de significados, con la finalidad de efectuar una enseñanza inclusiva que fomente el dialogo de saberes, y un aprendizaje significativo que brinde la posibilidad a los estudiantes de integrar sistemas de conocimiento para solucionar actividades académicas y/o de la vida cotidiana.

Finalmente, se solicita a los estudiantes leer el cuarto documento (Millán, C. 2013).

Sesión 3 
Revista Tecné, Episteme y Didaxis: TED. Año 2014, Número Extraordinario. ISSN Impreso: 0121-3814, ISSN web: 2323-0126 Memorias, Sexto Congreso Internacional sobre Formación de Profesores de Ciencias. 08 al 10 de octubre de 2014, Bogotá

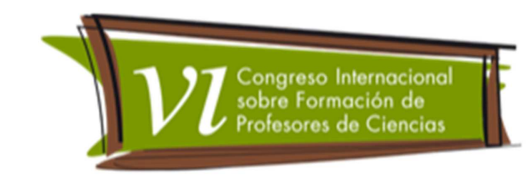

El propósito es visualizar la dinámica de la construcción del conocimiento, mediante relaciones dialógicas donde se intercambian conocimientos que generalmente son desconocidos por la divulgación científica y no permiten reconocer la diversidad cultural.

Se concluye que algunos cronistas de la Nueva Granada como Aguado (1582) escriben señalamientos por conveniencia, porque no es conveniente llegar y decir que los indígenas tenían conocimiento, debido a que es con la inferioridad del otro que se puede esclavizar para hacerlo dependiente y de esa forma verse como quien está a cargo de ese que no sabe nada. En los escritos de Gumilla (1741) se aprecia la utilidad del conocimiento de la botánica tradicional para la curación de enfermedades. Por otro lado, en los escritos de Hernández (1983) se evidencia el intercambio de conocimientos sin que Mutis reconociera la participación de la cultura tradicional en la construcción de conocimientos divulgados en la expedición botánica.

Con lo anterior, se concluye que la actualidad escolar necesita nuevas estrategias de intervención en el aula de clase que manifiesten un mundo propio y reconozcan una visión holística del conocimiento. Donde los maestros puedan revisar sus prácticas usuales de enseñanza y empiecen a construir espacios para el desarrollo de procesos educativos escolares y comunitarios que reivindiquen la diversidad cultural.

Finamente, se solicita a los estudiantes elaborar un ensayo sobre los temas discutidos durante las clases, en los cuales se identificaron las siguientes posturas:

Relación conocimiento ancestral y científico

Algunos estudiantes reconocen el intercambio entre el conocimiento de la medicina ancestral y la medicina moderna mediante el uso de plantas medicinales o fármacos derivados de plantas como fuente principal de una buena salud. Con lo anterior, se evidencia la integración del conocimiento tradicional en las ciencias.

Importancia de la etnoeducación

Algunos estudiantes reconocen en la etnoeducación una posibilidad de vincular, dignificar y direccionar el desarrollo cultural a través de una educación que valore la diversidad cultural y reconozca al otro, dejando a un lado el sometimiento y la opresión. 
Revista Tecné, Episteme y Didaxis: TED. Año 2014, Número Extraordinario. ISSN Impreso: 0121-3814, ISSN web: 2323-0126

Memorias, Sexto Congreso Internacional sobre Formación de Profesores de Ciencias. 08 al 10 de octubre de 2014, Bogotá

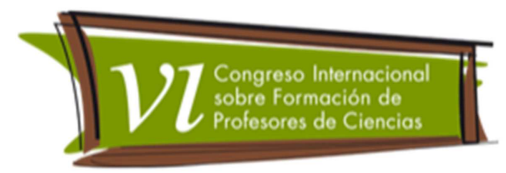

Interpretación de las culturas

Algunos estudiantes, interpretan la cultura como un entretejido simbólico a partir de quehaceres cotidianos. Otros estudiantes enuncian que si se identifican las características culturales de las poblaciones estudiantiles para incluirlas en la planificación del proceso enseñanza - aprendizaje, se podrían generar conocimientos significativos.

\section{Conclusiones}

Gracias al uso de la historia de las ciencias en el estudio de caso sobre la expedición botánica, los estudiantes trasforman la concepción de la ciencia alejada del carácter universal $\mathrm{o}$ de absoluta verdad y se propicia un reconocimiento en la actividad científica como sistema multicultural que se relaciona y se transforma con la integración de otros sistemas culturales.

Se evidencia en las intervenciones y en los ensayos escritos por los estudiantes que sus discursos incluyen que el conocimiento no debe ser jerarquizado debido a que es el producto de la integración de múltiples sistemas culturales y que las ciencias sufren transformaciones de acuerdo al contexto donde se desarrolle. Otro discurso, es integrar en los procesos de enseñanza - aprendizaje el conocimiento tradicional, las necesidades del contexto y la realidad de cada cultura, para diseñar estrategias de aprendizaje acorde a las necesidades de la comunidad.

Por lo anterior, se estima que hubo una ganancia debido a que los estudiantes cuestionaron desde la perspectiva sociocultural las formar de concebir las ciencias, relativizando nociones de verdad, cientificidad y objetividad, mediante interpretaciones que refutan la existencia de jerarquía o de superposición del conocimiento para aceptar la subjetividad ocasionada por conflictos de interpretaciones; y que esto a su vez genere en los estudiantes un pensamiento crítico en cuanto a la diversidad del conocimiento que circula en los sistemas culturales evidenciando la necesidad de una enseñanza de las ciencias que promueva la participación y el control cultural del conocimiento mediante el dialogo de saberes.

\section{Referencias Bibliográficas}

Aguado, F. (1582). Recopilación historial. (Tom. 1, pág. 598-599). Bogotá: Biblioteca de la Presidencia de la Colombia. 
Revista Tecné, Episteme y Didaxis: TED. Año 2014, Número Extraordinario. ISSN Impreso: 0121-3814, ISSN web: 2323-0126

Memorias, Sexto Congreso Internacional sobre Formación de Profesores de Ciencias. 08 al 10 de octubre de 2014, Bogotá

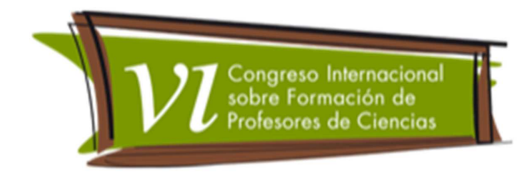

Colombia. Ministerio de educación nacional. Enseñar y aprender de la diversidad y en la diversidad, (s.f). Recuperado de http://www.mineducacion.gov.co/1621/article-208081.html

Elkana, Y. (1983). La ciencia como sistema cultural: una aproximación antropológica. Boletín sociedad colombiana de epistemología, 5, 1- 32.

Geertz, K. (2003). Interpretación de las culturas. (12a ed. pág. 17-40). Barcelona, España: Gedisa.

Guerra, A. (Productor). (2010). Súper O histórico (serie de televisión) Bogotá, Colombia. Señal Colombia. De http://www.youtube.com/watch?v=TYrN_2tZfn8

Gumilla, J. (1741). El Orinoco ilustrado. Historia natural, civil y geográfica de este gran río. (Tom. 1, pág. 274-283). Bogotá: Biblioteca Popular de la cultura de Colombia

Hernández, G. (1983). Escritos científicos de Don José Celestino Mutis. (Tom. 1, pág. 143-156). Bogotá: Editorial Kelly.

Millán, C. (2013). La inclusión histórica de la botánica ancestral en la enseñanza de las ciencias naturales. En prensa Universidad del Valle.

Pacheco, J. (Productor). (2012). Templo de las ratas (serie de televisión). Perú. Panorama. De. http://www.youtube.com/watch?v=bto8msdH6S8

Tinnaluck, Y. (2004). Ciencia moderna y conocimiento Nativo: Un proceso de colaboración que abre nuevas perspectivas para la PCST. Ciencia, Medicina, Comunicación y Cultura, (32), pág. 24-29. 